\title{
El artículo 925 del Código Civil. La verdadera querella de amparo
}

\author{
Mónica Jara Pérez*
}

\begin{abstract}
RESUMEN
La aparente antinomia existente entre los artículos 924 y 925 del Código Civil, relativos a la prueba de la posesión, ha sido tradicionalmente interpretada de manera insuficiente por la doctrina y jurisprudencia, al no hacerse cargo de la frase final del artículo 925 CC "ejecutados sin el consentimiento del que disputa la posesión". A raíz de lo señalado, tras cuestionar y replantear la interpretación tradicional efectuada por la jurisprudencia del artículo 925 CC, en virtud de un análisis histórico y sistémico, que relaciona los artículos 916, 920, 921, 923, y 924 del Código Civil, se concluye la coincidencia de los hechos descritos en la norma con el concepto de turbación o embarazo y la función de conservación de la posesión, postulando en definitiva la reestructuración de las acciones posesorias, en especial la Querella de Amparo, equivocadamente articulada a base del artículo 921 CC.
\end{abstract}

Posesión - turbación o embarazo - conservación

\section{Article 925 Civil Code. The true complaint for relief}

\begin{abstract}
The apparent contradiction that exists between Articles 924 and 925 of the Civil Code, related to proof of possession, has been interpreted traditionally in an insufficient manner due to doctrine and jurisprudence, by not giving weight to the final sentence of Article 925CC "executed without the consent of he who disputes the possession". Based on the indications, after a questioning and reformulation of the traditional interpretation made in jurisprudence of article 925 CC, by virtue of an historic and systemic analysis, which links articles 916, 921, 923 and 924 of the Civil Code, it is concluded that the coincidence of the events described in the norm with the concept of disturbance or hindrance and the function of the conservation of possession, definitively postulate the restructuring of actions of possession, in particular the Complaint for Relief, mistakenly articulated on the basis of article 921 CC.
\end{abstract}

Possession - disturbance or hindrance - conservation

* Magister en Derecho, Universidad Austral de Chile. Correo electrónico: monica.jara@uss.cl. Artículo recibido el 31 de agosto de 2015 y aceptado para su publicación el 30 de agosto de 2016. 


\section{Planteamiento}

$\mathrm{S}$ on muy pocas las materias que en Derecho Civil dividen más a la doctrina y a la jurisprudencia que lo relativo a la posesión de inmuebles. La divergencia abarca desde el concepto hasta la forma en que debe ser probada, decantando las opiniones en innumerables criterios que fundamentan teorías que buscan reconstruir el concepto y entregar una tesis coherente que permita resolver las incontables disputas, generadas esencialmente por un entramado necesario entre el concepto de posesión, el de prescripción adquisitiva, y el funcionamiento del sistema registral ${ }^{1}$. Lamentablemente, a pesar de los múltiples esfuerzos interpretativos, parece aún no vislumbrarse una pronta solución y tampoco es seguro que los operadores jurídicos la consideren necesaria. En este escenario, “... la posesión entre nosotros se ha erigido como uno de los símbolos de la complejidad jurídica en la teoría, y una fuente importante de litigios apasionados en el devenir de la práctica" ${ }^{2}$, destacando como tendencias centrales que intentan desentramar el conflicto, dos teorías cuyos "argumentos giran en torno a los mismos preceptos, que se armonizan o contraponen con variados razonamientos" 3 . Por una parte la teoría de la inscripción ficción; y opuesta a esta, la teoría de la inscripción garantía, respecto de cuyo conflicto irreconciliable deberemos inevitablemente pronunciarnos.

Uno de los principales factores que torna conflictivo el tema posesorio es la oscuridad y a veces contradicción de los textos ${ }^{4}$. En este sentido, los artículos $924^{5}$ y $925^{6}$ del Código Civil, contenidos en el título de las acciones posesorias y referentes, en opinión de la doctrina, a la prueba de la posesión, fundamentan separadamente teorías tan contradictorias como la confusión que arroja una lectura liviana de sus enunciados, sirviendo así el artículo 924 CC de fundamento a la teoría que otorga prevalencia a la inscripción en el registro ${ }^{7}$, y antagónicamente, su sucesor en el código sirve de argumento a aquella teoría que considera a la inscripción una garantía que resguarda una realidad material o, en resumen, a la posesión material ${ }^{8}$. La oscuridad de las normas en torno al tema es innegable ${ }^{9}$, y resulta al menos curioso que teorías opuestas se sustenten incluso

\footnotetext{
${ }^{1}$ Peñailillo, D., Los bienes, la propiedad y otros derechos reales, Editorial Jurídica de Chile, Santiago, 2006 p. 324.

${ }^{2}$ Ibidem.

${ }^{3}$ Peñailillo, D., op. cit., p. 386.

${ }^{4}$ Peñailillo, D., op. cit., p. 374.

${ }^{5}$ Artículo 924 CC. "La posesión de los derechos inscritos se prueba por la inscripción y mientras esta
} subsista, y con tal que haya durado un año completo, no es admisible ninguna prueba de posesión con que se pretenda impugnarla".

${ }^{6}$ Artículo 925 CC. "Se deberá probar la posesión del suelo por hechos positivos, de aquellos a que solo da derecho el dominio, como el corte de madera, la construcción de edificios, la de cerramientos, las plantaciones o sementeras, y otros de igual significación, ejecutados sin el consentimiento del que disputa la posesión".

${ }^{7}$ Peñailillo, D., Los bienes, la propiedad y otros derechos reales, Editorial Jurídica de Chile, Santiago 2006 p. 386.

${ }^{8}$ Peñailillo, D., op. cit., pp. 551 y 552.

9 "Pero admitamos que el pensamiento del legislador encerrado en este artículo 924, se oscurezca en atención a lo que se dispone en el artículo siguiente, el 925...". Trucco, H., “Teoría de la posesión inscrita dentro del Código Civil chileno”, en Revista de Derecho y Jurisprudencia, año VII, agosto de 1910, p. 135. 
en estos artículos contiguos. Las innumerables falencias de nuestro sistema de registro, el que genera incerteza al permitir, por ejemplo, la pervivencia de inscripciones paralelas, sumado a la insuficiencia en los textos legales, la falta de obligatoriedad del registro, su escasa legalidad, y las oscilaciones de la doctrina, convergen en incertidumbre, al definir el sentenciador de manera casuística las contiendas, inclinándose prudencialmente a favor de quien exhibe más antecedentes razonables ${ }^{10}$, en desmedro de una línea jurisprudencial consecuente y sostenida en el tiempo ${ }^{11}$. A raíz del panorama descrito, se torna prioritario efectuar un análisis profundo de las diversas normas que permita establecer reglas claras, por ejemplo, en cuanto a la prueba de la posesión, posibilitando a los litigantes asumir de manera consciente su defensa y prever un fallo adverso. Más aún, en ciertos casos como el descrito en los artículos 924 CC y 925 CC, consideramos necesario cuestionar si la interpretación tradicional que opone el contenido de ambas normas es correcta, o presenta falencias que impiden el adecuado entendimiento de lo prescrito por el legislador. Resulta por tanto sensato plantearnos $¿$ ha sido correctamente interpretado el artículo 925 CC en relación con el 924 CC?

\section{Antecedentes históricos}

Los antecedentes históricos del surgimiento de una norma son un elemento que debemos tener presente especialmente, en casos en los cuales aparentemente el legislador ha cometido errores tan manifiestos como en materia posesoria. En efecto, una lectura liviana de las normas 924 CC y 925 CC conduce a pensar que el legislador olvidó completamente el contenido del artículo 924 al escribir el 925. Desechando la hipótesis del olvido y buscando la correcta interpretación de las normas, es importante considerar que,

En el proyecto de 1853 se decía en términos generales: "se deberá probar la posesión por hechos positivos, etc...". En la comisión revisora, que habia aceptado para la tradición del dominio $y$ demás derechos reales (salvo las servidumbres), la inscripción del título en el Registro del Conservador de Bienes Raíces se agregó el art. 924 referente a la prueba de la posesión de los derechos inscritos, añadiendo al art. 925 las palabras; del suelo, después de posesión ${ }^{12}$.

La cita expuesta transparenta el importante hecho de que nuestro legislador, como explicitara en el mensaje del Código ${ }^{13}$, propendió mediante diversas normas ${ }^{14} \mathrm{a}$

${ }^{10}$ Peñailillo, D., op. cit., p. 9.387 y 389.

${ }^{11}$ En el mismo sentido, Varas, J., “¿Es el fisco dueño del sur de Chile?”, en Revista de Derecho Universidad Austral de Chile, Julio 2007, pp. 329-356.

${ }^{12}$ Claro Solar, L., Explicaciones de derecho civil chileno y comparado, Editorial Jurídica de Chile, Santiago, 1992, pp. 521-522

13 A mayor abundamiento, ver Trucco, H., "Teoría de la posesión inscrita dentro del Código Civil chileno", en Revista Derecho y Jurisprudencia, año VII, agosto de 1910, p. 135.

${ }^{14}$ V.gr. artículos del Código Civil: 724, según el cual la inscripción en el Registro del Conservador es la que hace "adquirir" la posesión; 696, solo cuando la inscripción se efectúa, se da o se transfiere "la 
la inclusión de los bienes inmuebles en un sistema de registro conservatorio. En este sentido, no es casual la adición del artículo 924 CC, y explícitamente de las palabras “del suelo" en el artículo 925 CC, cerrando con ello, en nuestra opinión, la posibilidad de probar posesión de derechos inscritos mediante simples actos materiales. A nuestro juicio, la historia de la norma revela cuál debería ser la correcta interpretación del artículo 925 CC, esto es, que tiene aplicación para probar posesión solamente en aquellos poco frecuentes casos en la actualidad, de bienes que no han sido incluidos en el sistema de registro del conservador. En los restantes casos de conflictos entre un poseedor inscrito y otro material, siempre prevalecerá la inscripción y la función del artículo 925 CC en virtud de su frase final, será configurar una acción posesoria que habilitará al poseedor del artículo 924 CC a solicitar la conservación de su derecho. De esta manera, un poseedor inscrito que vea vulnerados sus derechos frente a los actos materiales descritos en el artículo 925 CC, como "el corte de maderas, la construcción de edificios, la de cerramientos, las plantaciones o sementeras y otros de igual significación”, ejecutados sin su consentimiento, podrá recurrir por medio del procedimiento sumario ante el Juez de Letras correspondiente con el fin de solicitar que reestablezca el imperio del Derecho y pueda, como se explicará, tras acreditar los supuestos de hecho, conservar su posesión.

\section{INTERPRETACIÓN TRADICIONAL}

La jurisprudencia reciente de la Corte Suprema ${ }^{15}$ es conteste en señalar que el artículo 925 CC se aplica para probar la posesión de inmuebles sin título inscrito; aquellos cuya inscripción tiene menos de un año; resolver conflictos en caso de existir inscripciones paralelas; o para reforzar o robustecer la prueba de la posesión inscrita según las normas del artículo 924 CC. Así por ejemplo, en el 2010 la Corte Suprema resolviendo un recurso de casación en el fondo y en la forma, estableció:

El artículo 925 del Código Civil permite acudir a veces a la prueba de la posesión por hechos
positivos a que solo da derecho el dominio del suelo, sea para comprobar esa posesión, por

posesión efectiva del respectivo derecho”, 728 inc. $2^{\circ}$, dispone que el apoderamiento material de una cosa con ánimo de señor, no basta para constituir posesión si la cosa está inscrita; 730 inc. 2 en virtud del cual no hay adquisición ni pérdida de la posesión sin la "competente inscripción”; 2505 según el que no hay prescripción que valga contra un bien raíz inscrito, sino a virtud de una nueva inscripción. Trucco, H., “Teoría de la posesión inscrita dentro del Código Civil chileno”, en Revista Derecho y Jurisprudencia, año VII, agosto de 1910, pp. 133-134.

${ }^{15}$ Ver por ejemplo los siguientes fallos que recogen de manera consistente el mismo razonamiento al pronunciarse acerca de la materia: Saldaño Martínez, David con Cencosud Shopping Center, Corte Suprema, 22 de marzo de 2010 (Querella posesoria de amparo - Recurso de casación en el fondo); López Pérez, Eliana del C. con Álvarez Alvarado, Alfonso, Corte Suprema, 26 de octubre de 2010, (Juicio posesorio de amparo - Recurso de casación en el fondo); Invecsur Ltda. con Gatica Illanes Carlos y otro, Corte Suprema 18 de junio de 2007 (Querella posesoria de amparo - Recurso de Casación en el Fondo); Ejército Evangélico de Chile con Fernández Silva, Luis H., Corte Suprema 28 de enero de 2010 (Querella de amparo y restitución, Recurso de casación en el fondo y en la forma). 
ejemplo cuando se trata de inmuebles no inscritos, o para reforzar la prueba de la inscripción; para complementarla o para resolver el conflicto en caso de existir una serie de inscripciones paralelas y no ligadas entre sí; pero no es posible valerse de tales comprobaciones si se trata de posesión inscrita y ba durado un año o más.

La ley permite la prueba de la posesión por hechos a que solo da derecho el dominio, aun tratándose de inmuebles inscritos, cuando esa prueba tiene por objeto robustecer el mérito de la que arroja la inscripción, pero la inscripción de dominio en el Conservador de Bienes Raíces respectivo no puede ser desestimada ${ }^{16}$.

Esta interpretación que atribuye al artículo 925 CC una función esencialmente probatoria es amplia y resulta cómoda, especialmente en casos de inmuebles no inscritos para facilitar la prueba y solicitar la regularización de la posesión según las reglas del Decreto Ley 2695, pero es al menos dudosa, debido a la ubicación de la norma en el título de las acciones posesorias, y no en el de la posesión. En este último título, el artículo $724 \mathrm{CC}^{17}$ prescribe "Si la cosa es de aquellas cuya tradición deba hacerse por inscripción en el Registro del Conservador, nadie podrá adquirir la posesión de ella sino por este medio" 18 , por lo que, además, es contradictorio que se plantee la posibilidad de probar posesión del suelo por hechos positivos. Es factible preguntarse, entonces, si la real función del artículo es la sostenida por la jurisprudencia.

\section{CRÍTICA A LA INTERPRETACIÓN TRADICIONAL}

1. ¿Es imperioso reforzar una posesión inscrita por medio de los hechos que describe el artículo 925 CC?

La teoría de la posesión inscrita se hace cargo de la interpretación de la norma en su construcción argumentativa ${ }^{19}$, pero es imperativa al señalar que el título inscrito es suficiente prueba de posesión, y basta incluso frente a la ausencia de posesión material.

${ }^{16}$ Ejército Evangélico de Chile con Fernández Silva, Luis H., Corte Suprema, 28 de enero de 2010 (Querella de amparo y restitución, Recurso de casación en el fondo y en la forma).

${ }^{17}$ Los artículos 724 CC y 924 CC se encuentran en estrecha relación con el Mensaje XXI del Código Civil, "La transferencia y transmisión del dominio, la constitución de todo derecho real, exceptuadas, como he dicho, las servidumbres, exige una tradición; y la única forma de tradición que para estos actos corresponde es la inscripción en el Registro Conservatorio...". Barrientos, J,. Código Civil, LegalPublishing, Santiago, 2012, pp. 162 y 193.

${ }^{18}$ Refuerza esta idea el artículo 728: "Para que cese la posesión inscrita, es necesario que la inscripción se cancele, sea por voluntad de las partes, o por una nueva inscripción en que el poseedor inscrito transfiere su derecho a otro, o por decreto judicial.

Mientras subsista la inscripción, el que se apodera de la cosa a que se refiere el título inscrito no adquiere posesión de ella ni pone fin a la posesión existente".

${ }^{19}$ Para mayor abundamiento ver Trucco, H., op. cit., pp. 134-138. 
En este sentido la Corte Suprema al conocer de un recurso de Casación en el fondo, recogiendo la alegación de la parte recurrente, resolvió:

Se vulnera lo dispuesto en los artículos 582, 700, 724, 889, y 895 del Código Civil, al estimar que la ley exige posesión material al reivindicante para reputársele dueño, desconociéndose la aplicación de las normas antes citadas. Expone que la sentencia recurrida señala que la actora no es dueña, porque a su dominio le falta el elemento posesión corpus y que carece de legitimación activa por no haber acreditado el dominio de la propiedad que reivindica, faltando a dicho dominio la posesión material del inmueble, cometiendo de este modo los siguientes errores: 1.- Se desconoce la correcta interpretación del artículo 700 del Código Civil, que define la posesión de una cosa de forma genérica incluyendo bienes muebles e inmuebles; 2.- Se desecha el artículo 724 del Código Civil, que es norma especial para los inmuebles y por tanto prima sobre las normas generales... ${ }^{20}$.

Acorde a lo señalado por la doctrina tradicional argumentó la Corte Suprema en 2010:

En razón de lo dicho precedentemente, resulta manifiesto que el fallo ha tenido por probada la posesión del querellante recurriendo a pruebas distintas de la inscripción y solo ha dado por probada la existencia de hechos positivos a que solo da derecho el dominio sobre el mismo bien recurriendo a las pruebas aludidas, considerándolas como refuerzo de la que arroja la inscripción ${ }^{21}$.

Del tenor literal del artículo 924 CC en referencia a la inscripción ("No es admisible ninguna prueba de posesión con que se pretenda impugnarla"), extraemos que se trata de una presunción de Derecho, por lo que resulta al menos curioso y nos parece criticable que la jurisprudencia tradicional considere que la posesión en los términos del artículo 925 CC pueda apuntar a reforzar la prueba que otorga la inscripción, que como afirma reiteradamente y de forma correcta la jurisprudencia que recoge la teoría de la posesión inscrita, basta y sobra por sí misma. Distinto es transparentar el hecho que parece subyacente en la expresión "refuerzo”, consistente en que los sentenciadores

${ }^{20}$ Sociedad Comercial Turística e Inmobiliaria Lefincul Ltda. con Pichun Huenul, Ramón E., Corte Suprema 19 de julio de 2007 (Acción de reivindicación - Recurso de Casación en el Fondo).

En igual sentido se pronunció la Corte de Apelaciones de Santiago en 2013: "El testamento por el cual ella se hizo dueña -en comunidad- del bien raíz fue inscrito en el Registro competente el 8 de noviembre del año 2007, motivo por lo cual desde esa fecha la demandante es poseedora inscrita del inmueble cuya restitución reclama, argumento bastante para dar por satisfecho el primer requisito de la acción posesoria interpuesta. Todo ello es, incluso, sin considerar la posesión inscrita de sus antecesores sobre la misma propiedad, que puede anexar. Desde esa perspectiva, la exigencia de que la demandante cuente con "una posesión material" en el lapso de un año resulta innecesaria, pues sabido es que la inscripción de un bien inmueble en el registro competente es suficiente prueba y garantía de la posesión de ese bien raíz". Hernández Cárdenas Norma, con Carvajal Hernández Margarita, Corte de Apelaciones de Santiago, 3 de diciembre de 2013 (Querella posesoria de restitución - Recurso de Apelación).

${ }^{21}$ López Pérez, Eliana con Álvarez Alvarado, Alfonso, Corte Suprema, 26 de octubre de 2010 (Juicio posesorio de amparo - Recurso de casación en el fondo). 
deben hacerse cargo de la prueba aportada, la que en este caso más que robustecer puede confundir al litigante, que ex ante, frente a la duda de si resulta imperioso probar además hechos materiales, abultará innecesariamente su carga probatoria.

2. ¿Es el artículo 925 CC la regla para resolver conflictos en caso de existir inscripciones paralelas y no ligadas entre sí como postula la jurisprudencia tradicional?

No pueden existir dos personas con calidad de poseedores sobre un inmueble ${ }^{22}$. En el caso de inscripciones paralelas, se debe dilucidar la validez o prevalencia de una inscripción sobre la otra. En este sentido, la Corte de Apelaciones de Concepción, resolviendo un recurso de apelación, sentenció:

Que es una verdad axiomática en nuestro derecho positivo que la coexistencia de inscripciones paralelas y simultáneas referidas a un mismo y determinado predio vulnera a las claras el sistema de la posesión inscrita vigente. Arraigada la posesión de un bien raíz en una persona, es obvio que ella descarta la posibilidad de otra posesión contradictoria, como quiera que, tratándose del mismo bien no puede ser poseído por dos o más personas, en razón de que a ello se opone la naturaleza misma de la posesión que es singular, exclusiva, y no puede permanecer con otra posesión ${ }^{23}$.

Para resolver los casos de inmuebles sobre los que existen dos inscripciones aparentemente válidas, la jurisprudencia reciente de la Corte Suprema ha considerado diversos criterios. Así por ejemplo, en 2010 decidió:

La interpretación propuesta sigue los pasos de la tendencia llamada de la "inscripción garantía" que, en presencia de dos inscripciones vigentes respecto del mismo inmueble, obliga a entrar al análisis de sus respectivos antecedentes, para verificar cuál de los poseedores inscritos detenta solo la posesión teórica que le otorga la inscripción y cuál une a esta la posesión material, real y efectiva del o los inmuebles de que se trata, quien, en equidad y en la realidad de los bechos, presentaría un mejor derecho ${ }^{24}$.

Conociendo de un recurso de casación en el fondo en el 2011:

Concurre también a abonar la correcta resolución dada a la controversia en la sentencia recurrida el principio que la doctrina y la jurisprudencia estiman aplicable en situaciones como aquélla de que se trata en este juicio: el principio o criterio registral de prioridad-plasmado en el aforismo "prior in tempore potior in iure", de acuerdo con cuyo enunciado, entre varios

${ }^{22}$ Fallo de la Corte de Apelaciones de Concepción en RDJ, t.78, sección 2a , p. 136.

${ }^{23}$ Obando Fernández, Remigio con Rivas Rivas, Sergio, Corte de Apelaciones de Concepción, 31 de agosto de 1981 (querella de restablecimiento, recurso de apelación). En igual sentido Trucco, H., op. cit., p. 137.

${ }^{24}$ López López, Guillermo con Agrícola inmobiliaria Montolin S.A., Corte Suprema, 31 de agosto de 2010 (Acción reivindicatoria, recurso de casación en el fondo). 
derechos entre sí incompatibles debe prevalecer la protección al primer adquirente ${ }^{25}$ con la condición que la inscripción cronológicamente anterior no adolezca de vicios y reúna todos los requisitos establecidos por la ley para que el derecho que en ella se registra pueda surtir los efectos jurídicos que le son propios ${ }^{26}$.

Los casos analizados en los que con solo algunos meses de diferencia se ha pronunciado la Corte Suprema utilizando criterios dispares, como el de "inscripción garantía" o "registral de prioridad", y en general las situaciones en las que se deben resolver contiendas de inscripciones paralelas, resultan particularmente complejos ${ }^{27}$. Las cadenas de inscripciones suelen desligarse en estadios muy anteriores al enfrentamiento de los poseedores, presentando enajenaciones y transferencias simultáneas a terceros, muchas veces por la omisión del Conservador de plasmar la cancelación del dominio al margen de la inscripción ${ }^{28}$. Considerar el artículo 925 CC el adecuado para resolver este tipo de contiendas puede llevarnos al absurdo de que un tercero de manera fraudulenta inscriba una propiedad a su nombre, y tras probar actos menores como el haber cortado maderas en el inmueble, resulte vencedor frente al verdadero o justo poseedor, o regularice su posesión en virtud del Decreto Ley 2695. En este sentido:

La señora Domke no tenía título para justificar su ocupación y solo efectuó actos posesorios mínimos como argumento a esgrimir en su posterior solicitud de regularización. Es más, una vez que adquirió el dominio por prescripción, en lugar de construir su casa habitación, procedió derechamente a transferir el inmueble, el cual tenía un valor comercial muy superior a su avalúo fiscal ${ }^{29}$.

En contra de considerar el artículo 925 CC como el adecuado para resolver este tipo de contiendas, se pronuncia también Lucio Díaz Rodríguez:

El artículo 925 del Código Civil debe armonizarse con los dos artículos que le anteceden, puesto que la conclusión lógica es que quien tiene título inscrito a su favor está amparado frente al nuevo poseedor material, de suerte que el primero no necesita justificar los hechos positivos a que se refiere el artículo 925, porque la inscripción constituye para él pleno y

${ }^{25}$ En igual sentido Trucco, H., "Teoría de la posesión inscrita dentro del Código Civil chileno”, en Revista Derecho y Jurisprudencia, año VII, agosto de 1910, pp. 137-138. "Si alguien vende separadamente un mismo inmueble a dos personas y a las dos le hace entrega (única forma de hacerla es la inscripción), debe ser preferido aquel que primero inscribió (art. 1817 C.C.)".

${ }^{26}$ Jara Pinto, Elena con Díaz Lara, José, Corte Suprema 12 de mayo de 2011 (Acción de dominio o reivindicación, recurso de casación en el fondo).

27 Peñailillo, D., op. cit., pp. 282.

${ }^{28}$ Ver al respecto, Peñailillo, D., op. cit., pp. 280-283.

${ }^{29}$ Contra Jeanett Domke, infracción al art. 9 D.L. 2965. Rol 73.845, sentencia 31 de enero de 2000, Corte de Apelaciones de Puerto Montt. 
seguro resguardo, de tal manera que, probada ella, queda también acreditada ipso facto su posesión. La fuerza y el engaño serán siempre enemigos del derecho ${ }^{30}$.

En concordancia con lo expuesto, no resulta correcto postular que existe una regla de oro para resolver contiendas entre poseedores paralelos, ni menos que esta se encuentra contenida en el artículo 925 CC, por el contrario, creemos que se torna necesario efectuar un estudio acabado de los antecedentes invocados, considerando especialmente las justificantes de la posesión. En nuestro sistema registral dual, el antecedente jurídico o título no puede ser descartado al descansar solo sobre la posesión material, que por lo demás en los ejemplos del artículo 925 CC incluye actos nimios como plantaciones, corte de maderas o el cerramiento, que pueden desvirtuar la finalidad última del registro, que consiste en plasmar la historia fidedigna de las transferencias de propiedad.

\section{3. ¿Es el artículo 925 CC la norma base que permite probar posesión de inmuebles sin título inscrito?}

Para la doctrina tradicional, una de las funciones del artículo 925 CC consiste en posibilitar la prueba de la posesión de inmuebles no inscritos, opinión que compartimos. Es así como en los casos de inmuebles que jamás fueron incorporados al sistema registral, el artículo 925 CC emerge como una útil guía que permite la prueba de una posesión que conduzca a la obtención del dominio. Concordante con lo señalado, el Decreto Ley $2695^{31}$ que "Fija las normas para regular la posesión de la pequeña propiedad raíz y para la constitución del dominio sobre ella”, prescribe en su artículo cuatro: "La posesión material deberá acreditarse en la forma establecida en el artículo 925 del Código Civil ${ }^{32}$ ". De esta manera, la comprobación de la realización de actos como: “...el corte de maderas, la construcción de edificios, la de cerramientos, las plantaciones o sementeras y otros de igual significación...", unida al transcurso del plazo de cinco años, establecido por el número uno del artículo dos del Decreto Ley señalado, posibilitarían al solicitante la regularización de la posesión del bien raíz que ocupa.

${ }^{30}$ Ver Díaz Rodríguez, L., "Desafíos de nuestro sistema registral: ¿Reforma, renovación o actualización?”, en Revista de Derecho del Consejo de Defensa del Estado, N 3, abril 2001, p. 5.

31 "Actualmente, los textos fundamentales a los que se puede acudir para obtener el saneamiento son el DL. 2.695, sobre saneamiento de títulos de la pequeña propiedad raíz, rural y urbana y la Ley 16.741, sobre poblaciones en situación irregular". Peñailillo, D, op. cit., p. 286.

32 El inciso final del artículo citado agrega: "El solo hecho de existir una inscripción anterior que ampare el inmueble, no significará que el poseedor material esté reconociendo dominio ajeno, sin perjuicio de los derechos del titular de esa inscripción contemplados en el Título IV de la presente ley”. 


\section{Tratándose de inmuebles inscritos, ¿Permite la ley la prueba de la posesión por hechos a que solo da derecho el dominio?}

En el caso de los inmuebles inscritos, el Decreto Ley 2695 permite incluso que mediante la prueba de los hechos descritos en el artículo 925 CC se pueda obtener la regularización de la posesión sobre el inmueble en cuestión: "No será obstáculo para el ejercicio de este derecho la circunstancia de que existan inscripciones de dominio anteriores sobre el mismo inmueble" ${ }^{33}$. Si bien la situación descrita aparentemente contradice nuestro planteamiento, al atribuir al artículo 925 CC la función de posibilitar la prueba de la posesión, por sobre y en contra del tenor literal del artículo 924 CC, es necesario realizar ciertas prevenciones.

Frente a la posibilidad de obtener la regularización por hechos positivos contra un título inscrito, el Decreto citado establece ciertos mecanismos y estrictas medidas de publicidad que afirman la voluntad del legislador, de alertar al poseedor inscrito de las maniobras realizadas por parte del poseedor del artículo 925 CC para obtener el saneamiento del inmueble, y que por consiguiente pueda ejercer las acciones legales correspondientes para evitar la pérdida de su derecho. En primer lugar, mandata el artículo 5 del título I "Disposiciones generales", el deber de acompañar a la petición una declaración jurada en la que señale el conocimiento que tuviere de la existencia de inscripciones que se refieran al inmueble y de las otras personas que pudieran tener derechos sobre el predio. En cuanto a la publicidad de la petición, el título II "Del procedimiento" instituye rigurosas exigencias ya sea previas a la aceptación de la solicitud como la notificación mediante carta certificada a quien figura como propietario en los registros del Servicio de Impuestos Internos ${ }^{34}$, tanto posteriores a la aceptación, que consisten en la exhibición de la solicitud en lugares públicos determinados por un plazo de 15 días, publicación por dos veces en diario o periódico de los de mayor circulación regional, e incluso en zonas geográficas de difícil acceso, la difusión de la resolución mediante aviso radial. Sin duda, los mecanismos previstos tienen como finalidad poner en conocimiento del poseedor inscrito la intención de peticionario de saneamiento y sumar una cierta pasividad o inactividad del poseedor inscrito frente a la posesión de facto. Además de los requisitos referidos, el Decreto Ley contempla oportunidades para que el poseedor inscrito se oponga o impugne la solicitud del ocupante. En este sentido el artículo 11 inciso $3^{35}$ en relación con el 19 del Decreto Ley, establece un plazo de 30 días hábiles desde la publicación del último aviso para formular oposición a la solicitud

33 Articulo $2 \mathrm{n}^{\circ} 2$ inciso 2.

${ }^{34}$ El artículo 10 establece la obligación de oficiar al servicio de impuestos internos, con el fin de que informe el nombre, rol de avalúo de la propiedad y domicilio de quien aparece como propietario del inmueble. En caso de ser el dueño una persona natural, el Servicio deberá oficiar al registro civil e identificación y al servicio electoral para que informe el fallecimiento o el último domicilio, con el fin de notificar mediante carta certificada la solicitud.

${ }^{35}$ Ver concordancia entre los artículos 925 CC y 11 inc.3 en Barrientos, J., Código Civil, Legal Publishing, Santiago, 2012, p. 193. 
de regularización ${ }^{36}$. Posterior a la inscripción, el cuerpo normativo dispone el plazo de un año, contenido en el artículo 26 de la ley referida, para ejercer las acciones emanadas de los derechos reales de dominio, las que en caso de ser acogidas por el Tribunal, ordenarán como consecuencia la cancelación de la inscripción practicada, conservando su vigencia, las que existían sobre el inmueble con anterioridad. Transcurrido el plazo, las anteriores inscripciones de dominio se entenderán canceladas por el solo ministerio de la ley. Tras cumplir con las estrictas medidas de publicidad, practicada la inscripción del título a que da lugar la resolución emitida por el Servicio, el solicitante adquiere la calidad de poseedor regular, que lo habilita para adquirir el dominio por prescripción especial de un año. Por último, el artículo 28 del cuerpo legal favorece a los terceros que acrediten dominio sobre un inmueble o una parte de él, y que no hayan ejercido las acciones de los artículos 19 y 26, para que dentro del plazo de cinco años contados desde la inscripción, soliciten ante el juez de letras en lo civil, en cuyo territorio jurisdiccional se encuentre el predio, la compensación en dinero de sus derechos.

Como se ha demostrado, el legislador ha establecido siempre en las normas acerca de regulación y saneamiento una posición de privilegio para el derecho del poseedor inscrito, lo que queda de manifiesto en el establecimiento de rígidas medidas de publicidad para la solicitud efectuada por el poseedor material, la estipulación de plazos que permiten ejercer oposición e incluso el pago de indemnización dentro de los cinco años posteriores a la inscripción. El saneamiento de un bien inscrito basado en la realización de los hechos positivos que describe el artículo 925 CC constituye, por tanto, un castigo a la negligencia del poseedor inscrito primitivo y de ninguna manera representa la regla general en materia posesoria ${ }^{37}$.

\section{5. ¿Por qué la doctrina y jurisprudencia no incluyen en su interpretación la frase final del artículo 925 CC "ejecutados sin el consentimiento del que disputa la posesión"?}

El fragmento del fallo transcrito al principio de esta presentación grafica de forma certera cómo la jurisprudencia ha interpretado la norma desconociendo y no haciéndose cargo de la frase final citada, debido quizás a que no concuerda o armoniza con la finalidad eminentemente probatoria que le ha sido por tradición asignada. Sin embargo para comprender de manera cabal el alcance del artículo, es necesario que lo interpretemos

36 "Los avisos y carteles contendrán en forma extractada la resolución del Servicio, la individualización del peticionario, la ubicación y deslindes del inmueble, su denominación, si la tuviere, su superficie aproximada y la respectiva inscripción si fuere conocida, y en ellos deberá prevenirse que, si dentro del plazo de 30 días hábiles contados desde la publicación del último aviso, no se dedujere oposición por terceros, se ordenará la inscripción a nombre del solicitante".

37 En similar caso e igual sentido se pronuncia el profesor Humberto Trucco, quien señala: "quien deja que otro publique avisos y fije carteles diciéndose dueño de una propiedad inmueble, sin reclamar, por de pronto de los treinta días del inciso $4^{\circ}$ del art. 58 del Reglamento, y luego, dentro de los treinta años siguientes a la inscripción, es un propietario que bien merece la pérdida de los derechos que tan desdeñosamente abandona y sobre los cuales no sabe ser custodio celoso interesado". Trucco, H., "Teoría de la posesión inscrita dentro del Código Civil chileno”, en Revista Derecho y Jurisprudencia, año VII, agosto de 1910, p. 144-145. 
en su real extensión, pues no resulta lógico que el legislador incluya una frase estéril en una norma. A pesar de que el artículo 925 CC se encuentra contenido en el título XIII "De las acciones posesorias", no le ha sido otorgada históricamente tal función; ni en relación con otras normas ni menos aún por sí solo y, sin embargo, el tenor literal de su frase final reconoce abiertamente la existencia de una disputa en torno a la posesión. No parece casual que la frase final del artículo 925 CC suceda a aquella norma que plantea la exclusividad de la prueba por inscripción de derechos inscritos ni menos aún que clausure el artículo que tan contradictoriamente describe hechos positivos tras el enunciado "se deberá probar la posesión del suelo".

\section{REINTERPRETACIÓN}

Explorar la posibilidad consistente en que el artículo 925 CC sea la base de una acción posesoria nos obliga a entender cómo la doctrina tradicional ha estructurado las querellas de Amparo, Restitución y Restablecimiento ${ }^{38}$ y hacernos cargo de su relación con nuestra interpretación del artículo 925 CC, pues no tendría sentido que la nueva acción surgida del artículo en cuestión fuese una burda reiteración de aquello ya prescrito por el legislador. Coincidente con la finalidad de las acciones posesorias explicitada en el artículo 916 CC según el que: "Las acciones posesorias tienen por objeto conservar o recuperar la posesión de bienes raíces o de derechos reales constituidos en ellos”, la doctrina (basada en la terminología usada por el Código de Procedimiento Civil en su artículo 549), ha dividido las acciones según su fin en: acciones destinadas a conservar, restituir, y restablecer ${ }^{39}$.

\section{Querella de Amparo}

La Querella de Amparo, según opinión de la doctrina ${ }^{40}$, se encuentra consagrada en el artículo 921 CC "El poseedor tiene derecho para pedir que no se le turbe o embarace su posesión o se le despoje de ella, que se le indemnice del daño que ha recibido, y que se le dé seguridad contra el que fundadamente teme", y "Es la que tiene por objeto conservar la posesión de los bienes raíces y derechos reales constituidos en ellos" ${ }^{41}$. En relación con los artículos 916 CC y 924 CC, el querellante no ha perdido la posesión, y la acción precisamente tiene como finalidad poner fin a los hechos que, de continuar, pudieren concluir en privación o despojo. "En realidad las acciones posesorias tienen por objeto hacer respetar la posesión del poseedor de año completo contra todo acto que la desconozca; y este debe ser el objeto único de la querella de amparo, encaminada

\footnotetext{
38 Por razones metodológicas no hemos incluido las acciones posesorias especiales del título XIV.

39 Peñailillo, D., op. cit., p. 554-555.

${ }^{40}$ Peñailillo, D., op. cit., p. 555.

${ }^{41}$ Ibidem.
} 
a evitar que el despojo se consume" ${ }^{2}$. Estamos por tanto frente a hechos que turban o embarazan la posesión, por lo que además conjuntamente a la acción, el agraviado puede solicitar se le indemnice el daño causado, y se le dé seguridad contra el que, en terminología de la norma, fundadamente teme ${ }^{43}$.

En relación con el concepto de "turbación o embarazo", es importante vincularlo con los hechos que la doctrina y jurisprudencia comprenden dentro del mismo. En este sentido, "Tal como se desprende de sentencias en que ha sido aplicada, los hechos son de variada naturaleza: ingresos al predio, corta de árboles, extracción o ingreso de materiales, remoción de cercos, etc". 44

De este modo por ejemplo, la Corte de Apelaciones de La Serena, conociendo de un recurso de apelación, acogió una querella de amparo, basada en los siguientes hechos:

Fueron ejecutados trabajos con maquinaria pesada que importaron la demolición de una pirca y cercos que delimitaban por el lado sur, colindante con el Cerro Grande, las parcelas números 313 y 314 del Sector Santa Isabel, de Pampa Alta, cuya posesión detentan las querellantes 45 .

En 2010 la Corte Suprema, conociendo de un Recurso de Casación en el fondo, sostuvo:

Que la turbación del demandado se verificó en enero de 2005, cuando construyó en el inmueble una casa y que la querella se interpuso el 2 de junio de 2005, es decir, antes de cumplirse un año del acto que configura la molestia ${ }^{46}$.

Lo transcrito es coincidente con la opinión de la doctrina: “Turbación, embarazo o molestia causada a la posesión es todo acto o hecho voluntario, ejecutado de buena o mala fe que, sin despojar a otro de su posesión, supone disputar o controvertir el derecho de ejercerla que pretende tener el poseedor" ${ }^{4}$.

Como ha sido evidenciado, existe una enorme coincidencia entre los hechos considerados por la jurisprudencia y doctrina como turbación o embarazo, y los actos descritos en el artículo 925 CC "corte de maderas, la construcción de edificios, la de cerramientos, las plantaciones o sementeras, y otros de igual significación...”, revelando una estrecha vinculación entre el artículo 921 CC, querella de amparo, y la norma en estudio. Los

${ }^{42}$ Claro Solar, L., Explicaciones de Derecho Civil Chileno y Comparado, Editora Nacional Gabriela Mistral, Santiago, 1979, p. 516.

43 Ver Peñailillo D., op. cit., pp. 555-560.

${ }^{44}$ Peñailillo, D., op. cit., p. 555.

${ }^{45}$ Brito Zúñiga, María, y otros, con Pedemonte Massaccesi, Víctor, Corte de Apelaciones de La Serena, 28 de septiembre de 2012 (Querella posesoria de Amparo, Recurso de Apelación).

${ }^{46}$ López Pérez, Eliana del C. con Álvarez Alvarado, Alfonso, Corte Suprema, 26 de octubre de 2010, Juicio posesorio de amparo, Recurso de casación en el fondo.

${ }^{47}$ Peñailillo, op. cit., p. 555. 
actos descritos en el artículo 925 CC son, además, coincidentes con la finalidad que la doctrina atribuye a la querella de amparo del artículo 921 CC, ya que el querellante no ha perdido la posesión, la que en virtud del artículo 924 CC, por medio de la inscripción, sigue estando radicada en él. Poner fin a los actos que configuran la turbación o embarazo significa en definitiva la conservación de su derecho.

Antes de continuar con nuestra explicación, es necesario detenernos, ya que el repensar el artículo 925 CC en relación con la vinculación explicada con el artículo 921 $\mathrm{CC}$, entrega en un primer análisis las siguientes opciones argumentales:

- El artículo 925 CC complementa la hipótesis del artículo 921 CC, describiendo la forma en que se debe probar la turbación o embarazo.

- El artículo 925 CC se refiere a turbaciones o embarazos de hecho y el artículo 921 CC a hipótesis de derecho.

- El artículo 921 CC no distingue entre posesión inscrita o de hecho, por lo que cualquier poseedor podría invocarla. El artículo 925 CC, en cambio, hace referencia a la turbación sufrida por un poseedor inscrito.

- El artículo 921 CC hace referencia a la defensa de un poseedor frente a la regularización del DL 2695 impetrada por un poseedor de hecho, el artículo 925 CC, en tanto, contiene la verdadera querella de amparo.

Si bien las hipótesis enunciadas revelan que es posible construir un planteamiento que, partiendo de la base de la coincidencia de finalidad y terminología utilizadas por los artículos 921 CC y 925 CC, incorpore o se haga cargo de las posibilidades expuestas, a nuestro parecer, todas las opciones parten de un supuesto errado, consistente en que la finalidad del artículo 921 CC es ofrecer al poseedor una acción que posibilite solo conservar la posesión. Como fue expuesto, la doctrina es conteste en señalar que en el caso de la querella de amparo aún no se ha producido el despojo de la posesión, situación que en efecto habilitaría al agraviado para interponer una querella de restitución, basado en el artículo 926 CC "El que injustamente ha sido privado de la posesión, tendrá derecho para pedir que se le restituya, con indemnización de perjuicios”, pero sin embargo, el tenor literal del artículo 921 CC hace referencia a ambos supuestos: "El poseedor tiene derecho para pedir que no se le turbe o embarace su posesión o se le despoje de ella".

En nuestra opinión, la redacción del artículo $921 \mathrm{CC}^{48}$ es coincidente con el título que lo contiene, y las normas que le preceden tienen todas como finalidad aclarar el ámbito y forma de aplicación de las acciones posesorias. Estas últimas consideramos consagradas desde el artículo $925 \mathrm{CC}$ en adelante. Ahondaremos en aquello. El artículo 916 CC establece el objeto de las acciones posesorias "conservar o recuperar la posesión de bienes raíces o derechos reales constituidos en ellos"; el artículo 917 CC por su parte, limita el ámbito de aplicación excluyendo "las cosas que no pueden ganarse

${ }^{48}$ Artículo 921 CC. "El poseedor tiene derecho para impedir que no se le turbe o embarace su posesión o se le despoje de ella, que se le indemnice del daño que ha recibido, y que se le dé seguridad contra el que fundadamente teme". 
por prescripción como..."; el artículo 918 CC prescribe el requisito de plazo para tener legitimación activa "el que ha estado en posesión tranquila y no interrumpida un año completo" ; el artículo 919 CC ${ }^{49}$, concordante con su antecesor, establece la subrogación del heredero en las acciones del causante. Acorde con lo expuesto en los artículos 916 CC y 918 CC, el artículo 920 CC detalla la forma de computar el plazo "un año completo, contado desde el acto de molestia o embarazo" para las acciones que tienen por objeto conservar la posesión, y también de un año completo para las que tienen por objeto recuperarla, pero esta vez contado "desde que el poseedor anterior la ha perdido". El artículo $921 \mathrm{CC}$, postulamos, no contiene la querella de amparo, sino que ahonda y refuerza lo señalado por el artículo 916 CC, describiendo los derechos del poseedor agraviado, pudiendo en definitiva, tanto el que ha sufrido "turbación o embarazo" como el que ha sufrido "despojo", solicitar indemnización del daño y que se le dé seguridad contra el que fundadamente teme. Resulta lógico que el poseedor inscrito que ha sufrido turbación o embarazo a raíz de los actos descritos en el artículo 925 CC y otros de igual significación experimentó un detrimento patrimonial, ya sea directo, como en el caso del corte de maderas, o por privación de uso, como en la construcción de edificios. La seguridad contra el que fundadamente teme es también producto del eventual despojo, que de perpetuarse la turbación podría experimentar el poseedor del artículo 924 CC, ya que son precisamente estos hechos los que pueden fundar la solicitud de saneamiento en virtud del Decreto Ley 2695 "La posesión material deberá acreditarse en la forma establecida en el artículo 925 del Código Civil" ${ }^{50}$.

\section{Querella de Restitución}

El artículo 926 CC, a su vez, consagra la querella de restitución, "Que tiene por objeto recuperar la posesión de bienes raíces o derechos reales constituidos en ellos (arts. 916 y 926 del CC y 549 del CPC). El querellante ha sido ahora despojado de su posesión y por la querella pide que le sea restituida" 1 .

Congruente con nuestra postura, el artículo 926 CC emerge como corolario de los hechos descritos en el artículo 925 CC, y significa una nueva oportunidad de plazo para el poseedor inscrito, que en esta ocasión ha sido despojado de la posesión producto de una nueva inscripción. Frente a la disyuntiva examinada por la doctrina, de si corresponde la acción al poseedor inscrito que es despojado materialmente de su finca, nuestra postura es clara, negando la posibilidad de entablar querella posesoria, debido esencialmente, a que por graves que sean los hechos soportados, la inscripción persiste. El poseedor podrá interponer una querella de amparo frente a los hechos materiales, que en nuestra opinión configuran una turbación de su posesión, solicitando en definitiva al Tribunal la conservación de su derecho. Por lo explicado, frente a hechos como el corte

49 Artículo 919 CC. "El heredero tiene y está sujeto a las mismas acciones posesorias que tendría y a que estaría sujeto su autor, si viviese”.

50 Artículo $4^{\circ}$ Decreto Ley 2695.

51 Peñailillo, D., op. cit. 557 
y retiro de candado, instalación de uno propio, levantamiento de una especie de choza con maderas y planchas de zinc antiguos, que fundan la interposición de una querella de restitución ${ }^{52}$, no sería correcto acogerla, tal como sucedió en un caso:

Que estimándose que las declaraciones de los testigos del querellante son más verídicas, ellas también sirven para acreditar el despojo de la posesión sufrido por el actor, las que se hallan corroboradas por las copias de la denuncia interpuesta ante el Ministerio Público, que dan cuenta de la perturbación de la posesión por parte de la querellada ${ }^{53}$.

El párrafo del fallo transcrito evidencia además confusión de conceptos, al hacer sinónimo el despojo de la posesión, con la perturbación de la misma. En relación con el plazo para interponer la querella, este es de un año contado desde que el poseedor anterior ha sido despojado (art. 920 CC), o sea, siguiendo nuestra teoría, desde la nueva inscripción. El citado plazo está conforme al requisito del año completo de posesión para ser titular de acción posesoria: "el primer poseedor tiene un año para interponer acción y el nuevo aún no tiene protección porque no ha cumplido por su parte el plazo; al cumplirse el año, pierde la protección el primitivo poseedor y la adquiere el nuevo" 54 . No sería correcto por tanto sostener

Al ejercer la querella el querellante estará reconociendo que el querellado es poseedor, porque uno de los fundamentos de su acción será que ha perdido la posesión por la usurpación del querellado (o de un antecesor de este conforme al art-927 CC). ${ }^{55}$

La existencia del plazo de un año para interponer la acción, contado desde el despojo, evidencia que por consiguiente la posesión no se ha perdido por el poseedor primitivo, ni ha sido adquirida por el nuevo, teniendo como finalidad la querella, como lo sugiere su nombre, la "restitución" del derecho. Lo señalado es además coincidente con el plazo de un año que dispone el artículo 26 del Decreto Ley $2695^{56}$ en resguardo del poseedor inscrito, que tras la solicitud de saneamiento de un tercero ha visto cancelada su inscripción, para ejercer las acciones de dominio que estimaren asistirles, las que de ser acogidas, ordenarán la cancelación de la inscripción practicada, conservando

${ }^{52}$ Hechos relatados en escrito de demanda, causa Figueroa Jara Jorge con Sánchez Sánchez María, Juzgado de Letras y Garantía de Quintay, ROL 488-2012.

${ }^{53}$ Figueroa Jara Jorge con Sánchez Sánchez María, Corte de Apelaciones de Chillán, 15 de marzo de 2013 (Querella de restitución, Recurso de Apelación).

${ }^{54}$ Peñailillo, D., op. cit., p. 550.

55 Atria, F., "Derechos Reales", en Revista Derecho Universidad Adolfo Ibañez, año 2006, p. 51.

${ }^{56}$ Artículo 26, Decreto Ley 2695. Sin perjuicio de lo dispuesto en el artículo $19^{\circ}$ los terceros podrán, dentro del plazo de un año, contado desde la fecha de la inscripción del inmueble practicada por resolución administrativa o judicial, deducir ante el tribunal señalado en el artículo $20^{\circ}$ las acciones de dominio que estimen asistirles.

El procedimiento se ajustará a las reglas del juicio sumario establecido en el Título XI del Libro III, del Código de Procedimiento Civil. 
su plena vigencia, las que existían con anterioridad sobre el inmueble $\mathrm{e}^{57}$. Lo expuesto contradice además lo planteado por la jurisprudencia y cierta doctrina ${ }^{58}$, en el sentido que los hechos descritos en el artículo 925 CC se refieren a la prueba de la posesión de los títulos cuya data de inscripción es menor a un año.

Por último, siguiendo nuestra tesis, la querella de restitución presenta adicionalmente la ventaja de que el actor no necesitará probar su dominio de la cosa, como sucedería en el caso de aceptar la opinión, equivocada a nuestro juicio, de que es la acción reivindicatoria la adecuada siempre en el caso de pérdida de la inscripción, como siguiendo el razonamiento de la cita recién transcrita, postula Fernando Atria Lemaitre:

\begin{abstract}
Por consiguiente la querella de restitución no será nunca apropiada para recuperar la posesión de un inmueble inscrito: si ha mediado inscripción (aun de saneamiento, si procediera), será necesario el ejercicio de la acción reivindicatoria; si no ha habido nueva inscripción, se tratará a lo sumo de que la posesión ha sido turbada en el sentido de que se ha impedido al poseedor actuar respecto de la cosa como poseedor, y podrá ser apropiada la querella de amparo, pero no la de restitución 59 .
\end{abstract}

Resulta arbitrario restringir la aplicación de la norma solo a aquellos inmuebles cuya posesión no se encuentra inscrita, estableciendo en definitiva una carga probatoria más gravosa para el poseedor inscrito que deberá recurrir a la prueba del dominio, que para el no inscrito que podrá aducir actos posesorios materiales en los términos del artículo 925 CC. Evidentemente, una vez transcurrido el plazo de un año sin haber ejercido la querella de restitución, solo queda a salvo el restante término de cuatro años para que accione de reivindicación, pero ya no a favor del poseedor inscrito sino del dueño.

\title{
3. Querella de Restablecimiento
}

En relación con la Querella de Restablecimiento, la doctrina tradicional incorpora dentro de las acciones posesorias esta figura surgida de la interpretación del artículo 928 del Código Civil ${ }^{60}$, considerando "que se concede al que ha sido despojado violentamente

${ }^{57}$ Artículo 27 Decreto Ley 2695. "Si el Tribunal acogiere la acción a que se refiere el artículo anterior, ordenará la cancelación de la inscripción practicada con arreglo a esta ley conservando su plena vigencia las inscripciones que existían sobre el inmueble con anterioridad a ella".

58 Trucco, H., “Teoría de la posesión inscrita dentro del Código Civil chileno”, en Revista Derecho y Jurisprudencia, año VII, agosto de 1910, p. 137.

59 Atria, F., "Derechos Reales", en Revista Derecho Universidad Adolfo Ibáñez, año 2006, p. 52.

${ }^{60}$ Artículo 928 CC. "Todo el que violentamente ha sido despojado, sea de la posesión, sea de la mera tenencia, y que por poseer a nombre de otro, o por no haber poseído bastante tiempo, o por otra causa cualquiera, no pudiere instaurar acción posesoria, tendrá sin embargo derecho para que se restablezcan las cosas en el estado que antes se hallaban, sin que para eso necesite probar más que el despojo violento, ni se le pueda objetar clandestinidad o despojo anterior. Este derecho prescribe en seis meses". 
de la posesión o mera tenencia de un inmueble, con el fin de que le sea restituido en el estado existente antes del acto de violencia (arts. 928 del CC. y 549 del CPC.)"61.

Resulta contradictorio con lo sostenido a lo largo de nuestro análisis la posibilidad de que mediante hechos violentos se produzca el despojo de la posesión. En efecto, se torna incluso irrisorio imaginar una hipótesis en la que por medio de la violencia se logre inscribir un inmueble. Sin embargo a nuestro juicio, la acción que configura el artículo 928 CC está lejos de ser una posesoria ${ }^{62}$, o al menos no en el mismo sentido que prescribe el artículo 916 CC.

Como correctamente afirma la jurisprudencia, "las acciones posesorias tienen por objeto conservar o recuperar la posesión de bienes raíces o derechos reales constituidos en ellos, y se dirige contra la persona que causa perturbaciones o priva a otro de la posesión, sin atender al derecho que esta persona pretenda"63. La querella de restablecimiento, alejándose de lo señalado y como su nombre lo indica, busca devolver o restablecer las cosas a su estado anterior, el que resultó alterado materialmente por actos ilegítimos. Además de la diferencia de finalidad expuesta, es al menos extraño que incluso el mero tenedor pueda ejercerla; que el actor no necesite probar posesión; y que por lo mismo, tampoco el plazo de un año de estabilidad posesoria sea requerido, como sucede en las querellas de amparo y restitución. Como conclusión de lo anterior, un ocupante o mero tenedor de corta data podría, frente al despojo ejecutado por el poseedor del artículo 924 CC o aun del dueño, defenderse de los actos materiales de despojo probando solamente que ha sufrido aquellos.

En igual sentido se pronunció la Corte Suprema en $2013^{64}$ :

Que, la parte querellada basa su defensa en la certeza que le dan los títulos de dominio en cuanto al límite de ambas propiedades en disputa, señalando la existencia de dominio de la querellada hasta el límite consistente en el estero Cun Cun. Sin embargo, el tribunal entiende que el juicio que nos convoca no es de dominio, como en sus declaraciones parecen entenderlo los testigos de la querellada. La forma que ha utilizado la querellada para restablecer el límite que ellos estiman es el correcto no ha sido la adecuada, porque no podían desconocer que por años el señor Batarce y su familia ejercían posesión sobre dicho terreno al mantener un jardín con plantas, flores, arbustos y pasto que fue destruido por orden de la querellada a fin de sacar un antiguo cerco existente y poner uno nuevo a orillas del estero ${ }^{65}$.

61 Peñailillo, D., op. cit., p. 558.

${ }^{62}$ En el mismo sentido Alessandri, A., Somarriva, M., Vodanovic, A., Tratado de los Derechos Reales, Temis S.A. y Editorial Jurídica de Chile, Santiago, 2001, tomo II, p. 304.

${ }^{63}$ Figueroa Jara Jorge con Sánchez Sánchez María, Corte de Apelaciones de Chillán, 15 de marzo de 2013 (Querella posesoria de restitución - Recurso de apelación).

${ }^{64}$ Batarce Mufdi, Jaime Andrés con Sociedad Inmobiliaria San Andrés Limitada, Corte Suprema, 8 de agosto de 2013 (Querella de restablecimiento - Casación de Oficio).

${ }^{65}$ Considerando $6^{\circ}$ del fallo de primera instancia dictado por el Tribunal de Los Lagos, que acogió la querella de restitución, decisión confirmada por la Corte Suprema. 
Estamos frente a una acción distinta, una que se aparta de la lógica de las acciones posesorias estudiadas $^{66}$, beneficiando incluso al que materialmente ocupa un inmueble, frente al despojo violento de esa ocupación por parte del dueño, ya que compartiendo la opinión de la doctrina, creemos que busca evitar la autotutela o justicia de propia mano ${ }^{67}$, como prosigue estableciendo el fallo recién citado:

La querella de restablecimiento busca evitar que las partes solucionen sus conflictos de tierra mediante justicia a propia mano. Los querellantes no podían desconocer a lo menos mera tolerancia por su parte o sus antecesores en cuanto a la ocupación que el señor Batarce y familia hacía de un retazo de terreno ubicado al otro lado del estero Cun Cun, pues no han ejercido las acciones posesorias a su debido tiempo en caso que se hayan sentido pasados a llevar en su posesión inscrita, ni tampoco se ha discutido la propiedad del terreno en disputa en el marco de las acciones pertinentes, lo que resulta fundamental en casos de esta naturaleza por el cual si aquél terreno debía restituírsele, la parte contraria tenía derecho para cobrar las mejoras que correspondiesen, cuestión que ha sido desconocida con el actuar violento de la parte querellada ${ }^{68}$.

El fallo transcrito además concluye acertadamente acerca de la posición de privilegio del poseedor inscrito, que le permite defenderse frente a las turbaciones descritas mediante diversas acciones, dentro de las cuales se encuentran la de amparo y restitución estudiadas. En ese sentido podemos concluir que si bien la querella de restitución hace referencia al "despojo de la posesión", lo que protege realmente es la apariencia de poseedor del ocupante, evitando que el dueño o poseedor inscrito lo arroje violentamente para evitar, por ejemplo, el cumplimiento de plazo o la ejecución de actos como los descritos en el artículo 925 CC que le permitan solicitar el saneamiento del inmueble, soslayando por medio de la fuerza, la vía legal.

\section{Acción posesoria del artículo 925 Del Código Civil. La verdadera Querella de Amparo}

A raíz de las inconsistencias de sostener la interpretación tradicional de la jurisprudencia, la ausencia de pronunciamiento respecto de la frase final del artículo 925 CC “...ejecutados sin el consentimiento del que disputa la posesión”, y la reinterpretación efectuada de la función del artículo 921 CC, es posible plantear la posibilidad lógica de que siguiendo la teoría de la posesión inscrita, debido a la ubicación de la norma, configure en relación con los artículos del Código Civil 916, 920, 921, 923 y 924, la

${ }^{66}$ En este sentido ver Alessandri, A., Somarriva, M., Vodanovic, A., Tratado de los Derechos Reales, Temis S.A. y Editorial Jurídica de Chile, Santiago, 2001, tomo II, p. 304.

${ }^{67}$ En igual sentido, Peñailillo D., op. cit., p. 558.

${ }^{68}$ Batarce Mufdi, Jaime Andrés con Sociedad Inmobiliaria San Andrés Limitada, Corte Suprema, 8 de agosto de 2013 (Querella de restablecimiento - Casación de Oficio). 
acción posesoria de amparo, que pretende posibilitar al poseedor inscrito la prueba de que un tercero materialmente ejecuta acciones propias del dominio sin su consentimiento, y por supuesto sin título que lo ampare, pudiendo conservar la posesión por conducto del procedimiento sumario. Lo planteado en relación con la configuración de una acción posesoria es coincidente con lo postulado por el profesor Paulino Alfonso del Barrio, quien en una anotación manuscrita inédita al margen del artículo 925 del Código Civil con el que dictaba clases, escribió ${ }^{69}$ :

\section{Parece que corresponde esta acción aun al poseedor inscrito que es privado de la posesión material. Hai evidentemente una anomalía en que se autorice para intentar acción posesoria para recuperar la posesión a quien en concepto de la lei no la ha perdido, anomalía que proce- de del sistema artificial de la inscripción. Por lo demás, no sería posible que el poseedor inscri- to se encontrase a este respecto en peor condición que el no inscrito.}

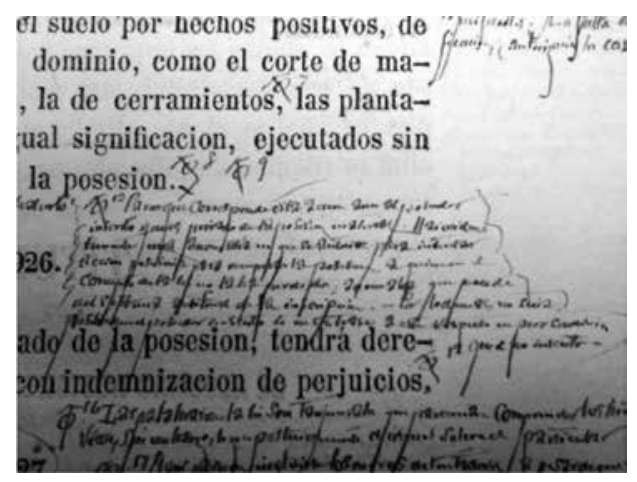

Consideramos que es correcto sostener que el artículo 925 CC alberga una acción posesoria, pero es equivocado, como explicaremos, plantear que tiene como objetivo recuperar la posesión. El artículo 916 CC establece la finalidad de las acciones posesorias, de "conservar o recuperar la posesión de bienes raíces" y el artículo 920 CC la forma de computar el plazo de un año desde "el acto de molestia o embarazo inferido a ella". Considerando que el tenor literal del artículo 924 CC prescribe expresamente que el poseedor inscrito no pierde la posesión por actos materiales, los hechos que enumera el artículo 925 CC no configurarían una acción que pretenda recuperar la posesión, pero sí encuadrarían en la hipótesis del inciso primero del artículo 920 CC de conservar la posesión, y resguardarse frente a actos como "el corte de maderas, la construcción de edificios, la de cerramientos, las plantaciones o sementeras, y otras de igual significación” ejecutados en el bien raíz sin su consentimiento. Esta idea se ve reforzada por la expresión "desde el acto de molestia o embarazo inferido a ella", que es coincidente con los hechos descritos en el artículo 925 CC.

Frente a estos hechos, siguiendo la tesis que postula este trabajo, el poseedor del artículo 924 CC podría exhibir contra el tercero que sin su consentimiento ejecuta actos

${ }^{69}$ La nota fue descubierta casualmente durante una reunión, en la que tras plantear la hipótesis de investigación al profesor patrocinante, Dr. Juan Andrés Varas, revisó un antiguo Código Civil de la primera edición heredado de su bisabuelo, para verificar si el art. 925 CC era una norma originaria. 
materiales a los que solo da derecho el dominio, el título del bien raíz para acreditar su posesión sumariamente en los términos del artículo 923 CC, y de esta forma defenderse, conservando su posesión y obteniendo conjuntamente "que se le indemnice el daño que ha recibido y que se le dé seguridad contra el que fundadamente teme”, en los términos del artículo 921 CC que, como evidenciamos, otorga dicho derecho tanto al que pretende conservar como al que persigue recuperar la posesión. La naturaleza de la acción que configurarían los artículos reseñados, es parcialmente complementaria a la doctrina tradicional, pues solo frente a la inexistencia de título inscrito el artículo 925 CC cumpliría una función probatoria en favor del poseedor material, "Se deberá probar la posesión del suelo por hechos positivos, de aquellos a que solo da derecho el dominio”, sirviendo los actos reseñados por el artículo ${ }^{70}$ de argumento para, por ejemplo, solicitar la regularización de la posesión. El caso de un conflicto de poseedores sobre un bien raíz, en el que uno posee título inscrito y el otro realiza actos materiales, se resuelve como prescribe el tenor literal del artículo 924 CC a favor del poseedor inscrito, hipótesis que se reafirma con la frase final del artículo 925 CC, "ejecutados sin el consentimiento del que disputa la posesión”. En este sentido, es importante destacar, como ha sido expuesto en nuestro estudio, que el poseedor material del artículo 925 CC puede mediante el procedimiento de saneamiento establecido en el Decreto Ley 2695, convertirse en un poseedor inscrito que obtenga, tras el plazo especial de un año desde la inscripción, el dominio del bien que ocupa, castigando de esta manera la desidia de, por ejemplo, un poseedor amparado en una inscripción de papel ${ }^{71}$. En contraposición, una larga ocupación basada en actos materiales como los descritos en el artículo 925 CC, carece de protección jurídica ${ }^{72}$ debido al mismo criterio subyacente Nemo auditur propriam turpitudinem allegans.

\section{BIBLIOGRAFÍA}

Alessandri, Arturo, Somarriva, Manuel, Vodanovic, Antonio, Tratado de los Derechos Reales, Temis S.A. y Jurídica de Chile, Santiago, 2001.

Atria Lemaitre, Fernando, "Derechos Reales", Revista Derecho Universidad Adolfo Ibánez, Santiago, año 2006.

Barrientos Grandón, Javier, Código Civil, LegalPublishing, Santiago, 2012.

Claro Solar, Luis, Explicaciones de derecho civil chileno y comparado, Editorial Jurídica de Chile, Santiago, 1992.

70 "Esto fluye de lo dispuesto en los arts. 728 , inc. $2^{\circ}, 729$ y 2505 , ya tantas veces citados, y sobre todo del art. 925, según el cual, volvemos a repetir, la posesión de los inmuebles no inscritos se prueba por el corte de maderas, la construcción de cerramientos etc., etc.”. Trucco, H., “Teoría de la posesión inscrita dentro del Código Civil chileno", en Revista Derecho y Jurisprudencia, año VII, agosto de 1910, p. 140.

71 "Inscripciones de cosas que nunca se han poseído". Urrutia, L., "Vulgarización sobre la posesión ante el Código Civil chileno”, en Revista Derecho y Jurisprudencia, año XXXI, marzo y abril de 1934, p. 11.

${ }^{72}$ Salvo la querella de restablecimiento frente al despojo violento, en los términos antes explicitados. 
Claro Solar, Luis, Explicaciones de derecho civil chileno y comparado, Editora Nacional Gabriela Mistral, Santiago, 1979.

Díaz Rodríguez, Lucio, "Desafíos de nuestro sistema registral: ¿Reforma, renovación o actualización?" Revista de Derecho del Consejo de Defensa del Estado, N³, abril 2001.

Peñailillo Arévalo, Daniel, Los bienes la propiedad y otros derechos reales, Editorial Jurídica de Chile, Santiago, 2006.

Trucco Franzani, Humberto, “Teoría de la posesión inscrita dentro del Código Civil chileno”, Revista Derecho y Jurisprudencia, año VII, agosto de 1910.

Urrutia Anguita, Leopoldo, "Vulgarización sobre la posesión ante el Código Civil chileno", Revista Derecho y Jurisprudencia, año XXXI, marzo y abril de 1934.

VAras Braun, Juan Andrés, “¿Es el fisco dueño del sur de Chile?”, Revista de Derecho Universidad Austral de Chile, Valdivia, julio 2007. 